\title{
Response to Drs. Herring and Grundmann
}

\section{To the Editor:}

We thank you for the opportunity to respond to the important points raised by Drs. Herring and Grundmann in their comment, "The IRF6 p.274V polymorphism is not a risk factor for isolated cleft lip." These authors raise a critical point regarding population-based risk factors versus those relevant to individual cases. As they correctly point out, isolated forms of cleft lip and palate have a complex etiology with multiple genetic and environmental factors contributing to causal mechanisms. Thus, it is unlikely that any single genetic factor can explain a large portion of that clefting risk. The findings reported in Zucchero et al. ${ }^{1}$ identified the common "V" variant as a risk factor that was highest in Asian or South American populations and far less so in European populations. However, our article discussed not only the V274I variant but also the more general genetic background in which it resided, including an extensive hap- lotype analysis of an additional 35 SNPs surrounding the IRF6 gene. In the aggregate, haplotypes that include p.274V variant did generate both the overall population-specific association quoted in the article as well as a 3 -fold increased risk for clefting recurrence in families when compared to population-based data on recurrence risk in a Filipino population. ${ }^{2}$ It was unclear to us why Drs. Herring and Grundmann did not incorporate into their analysis the additional SNP variants we reported given that the haplotype analysis provides the most accurate risk estimates, particularly in European populations. In addition, as we acknowledged within the article, we do not believe that the V274I variant itself is likely etiologic but rather that it resides on a haplotype on which another mutation, yet to be identified, is the specific risk factor. Most importantly, this haplotype-based analysis has recently been confirmed in a Southern European population by Scapoli et al. ${ }^{3}$ 
We agree with the comments of Drs. Herring and Grundmann that the V274I variant itself is not yet useful for genetic counseling in individual families. This will await more specific identification of the risk allele within those haplotypes conferring greatest risk, which may be different in groups of different ancestral origins. Nonetheless, as they acknowledge, we have already made substantial strides in identifying risk factors for isolated forms of clefting through the identification of phenocopies of some recognized genes such as MSX1, 4,5 IRF6, ${ }^{1,3}$ TBX22, ${ }^{6}$ and FGFR $1 .{ }^{7}$ Although it may not yet be time to apply risk analysis to individual families until further information is available for IRF6, we nonetheless disagree with the title of the comment in that we believe that both the work of Zucchero et al., ${ }^{1}$ and the confirmation data of Scapoli et al., ${ }^{3}$ clearly identify this polymorphism as a risk factor for clefting across a range of different populations.

Mary L. Marazita, PhD, FACMG School of Dental Medicine Division of Oral Biology/Genetics Research Pittsburgh, Pennsylvania

Jeffrey C. Murray, MD, FACMG, FAAP Department of Pediatrics University of Iowa Iowa City, Iowa

Theresa Zucchero Departments of Pediatrics and Genetics Graduate Program University of Iowa Iowa City, Iowa

\section{References}

1. Zucchero TM, Cooper ME, Maher BS, Daack-Hirsch S, Nepomuceno B, Ribeiro L, Caprau D et al. Interferon regulatory factor 6 (IRF6) is a modifier for isolated cleft lip and palate. N Engl J Med 2004;351:769-780.

2. Murray JC, Daack-Hirsch S, Buetow KH, Munger R, Espina L, Paglinawan N et al. Clinical and epidemiologic studies of cleft lip and palate in the Philippines. Cleft Palate J 1997;34:7-10.

3. Scapoli L, Palmieri A, Martinelli M, Pezzetti F, Carinci P, Tognon M et al. Strong evidence of linkage disequilibrium between polymorphisms at the IRF6 locus and nonsyndromic cleft lip with or without cleft palate, in an italian population. Am J Hum Genet 2005;76:180-183.

4. van den Boogaard, MJ, Dorland M, Beemer FA, van Amstel HK. MSX1 mutation is associated with orofacial clefting and tooth agenesis in humans. Nat Genet 2000;24: 342-343.

5. Jezewski PA, Vieira AR, Nishimura C, Ludwig B, Johnson M, O’Brien SE et al. Complete sequencing shows a role for MSX1 in non-syndromic cleft lip and palate. J Med Genet 2003;40:399-407.

6. Marcano AC, Doudney K, Braybrook C, Squires R, Patton MA, Lees MM et al. TBX22 mutations are a frequent cause of cleft palate. J Med Genet 2004;41:68-74.

7. Dode C, Levilliers J, Dupont JM, De Paepe A, Le Du N, Soussi-Yanicostas N et al. Loss-of-function mutations in FGFR1 cause autosomal dominant Kallmann syndrome. Nat Genet 2003;33:463-465. 